\title{
EVALUASI PEMBERIAN CACING TANAH Eisenia foetida DAN MULSA TERHADAP PERTUMBUHAN DAN KUALITAS TANAMAN Sorghum bicolor PADA TANAH LATOSOL DRAMAGA
}

\author{
Asep Tata Permana ${ }^{1}$, Luki Abdullah ${ }^{2}$, Panca Dewi M. H. K. ${ }^{2}$, dan Suwarno ${ }^{3}$ \\ ${ }^{1}$ Program Studi IImu Nutrisi dan Pakan, Sekolah Pascasarjana, IPB University, Bogor-Jawa Barat \\ ${ }^{2}$ Departemen IImu Nutrisi dan Teknologi Pakan, Fakultas Peternakan, IPB University, Bogor-Jawa Barat \\ ${ }^{3}$ Departemen IImu Tanah dan Sumberdaya Lahan, Fakultas Pertanian, IPB University, Bogor-Jawa Barat \\ e-mail: aseptp@gmail.com
}

\begin{abstract}
ABSTRAK
Penelitian ini bertujuan untuk mengevaluasi pemberian cacing tanah Eisenia foetida dan pemberian mulsa pada media tanam terhadap pertumbuhan dan kualitas tanaman Sorghum bicolor. Penelitian dilakukan di rumah kaca Laboratorium Agrostologi, Fakultas Peternakan IPB pada tahun 2017. Rancangan percobaan yang digunakan adalah rancangan acak lengkap pola faktorial dengan dua faktor, yaitu faktor cacing tanah E. foetida (o dan 60 cacing.pot $^{-1}$ ), serta faktor mulsa (tanpa mulsa, mulsa organik, mulsa anorganik). Semua perlakuan dilakukan pengulangan sebanyak 3 kali. Tanah yang digunakan adalah tanah latosol Dramaga yang telah dikeringkan dan diayak dengan ayakan $5 \mathrm{~mm}$. Jumlah tanah yang digunakan adalah $5 \mathrm{~kg}$ BKU (berat kering udara) tiap pot. Panen Sorghum bicolor dilakukan 6o HST (hari setelah tanam). Pemberian cacing sangat nyata meningkatkan berat kering akar, daun dan tajuk tanaman. Pemberian mulsa tidak memberikan perbedaan yang nyata terhadap semua parameter tanaman. Terdapat interaksi antara cacing dan mulsa terhadap akumulasi $\mathrm{N}$ tanaman. Pemberian mulsa organik memberikan peningkatan yang nyata jumlah cacing dibandingkan dengan pemberian mulsa anorganik. Pemberian cacing menunjukkan manfaat terhadap produktivitas tanaman Sorghum bicolor dimana manfaatnya akan lebih besar apabila dikombinasikan dengan pemberian mulsa organik.
\end{abstract}

Kata kunci: Eisenia foetida, Sorghum bicolor, latosol, mulsa

\section{EVALUATION OF EISENIA FOETIDA EARTHWORMS AND MULCH APPLICATION ON THE GROWTH AND THE QUALITY OF SORGHUM BICOLOR PLANT IN DRAMAGA LATOSOL SOIL}

\begin{abstract}
The aim of this study was to evaluate the application of $E$. foetida earthworms and mulch on the growing media on the growth and the quality of the Sorghum bicolor plant. The study was conducted in the greenhouse of the Agrostology Laboratory, Faculty of Animal Science IPB University in 2017. The experimental design used was a completely randomized design, factorial pattern with two factors. First factor was $E$. foetida earthworm factor (o and 60 earthworm pot ${ }^{-1}$ ), and the second factor was mulch (without mulch, organic mulch, inorganic mulch). All treatments were repeated 3 times. The soil used was Dramaga latosol soil that has been dried and sifted with a $5 \mathrm{~mm}$ sieve. The amount of soil used was $5 \mathrm{~kg}$ BKU (air dry weight) per pot. Sorghum bicolor plant was harvested 60 days after planting. The application of earthworms very significant increased the dry weight of roots, leaves and canopy (upper part) of plants. Mulch application did not give a significant difference for all plant variables. There was an interaction between earthworms and mulch on the accumulation of $\mathrm{N}$ plants. Application of organic mulch gives a significant increase in the number of earthworms compared to inorganic mulch. The application of earthworms gave the benefits of Sorghum bicolor plant productivity, the benefits will be greater if combined with organic mulch.
\end{abstract}

Keywords: Eisenia foetida, Sorghum bicolor, latosol, mulsa 


\section{PENDAHULUAN}

Tanah latosol merupakan salah satu tanah masam yang penyebarannya di Indonesia cukup luas yaitu mempunyai luasan sekitar 84,63 juta hektar (Djaenudin, 2008). Penanaman tanaman pada tanah masam menghadapi kendala diantaranya $\mathrm{pH}$ tanah yang rendah, kandungan $\mathrm{Al}$ dan $\mathrm{Fe}$ yang tinggi yang dapat menyebabkan tanaman keracunan, serta kandungan unsur hara di dalam tanah yang rendah.

Dalam upaya mengatasi kemasaman tanah dan kandungan $\mathrm{Al}$ dan $\mathrm{Fe}$ yang tinggi biasanya dilakukan pengapuran (Subandi dan Wijanarko, 2013) serta penambahan pupuk dan bahan organik/ bahan hayati (Wijanarko dan Taufiq, 2004). Dalam penelitian ini untuk penambahan kesuburan tanah adalah dengan menambahkan cacing Eisenia foetida. Cacing $E$. foetida yang merupakan cacing yang biasa digunakan untuk pembuatan vermikompos (kompos yang pembuatannya menggunakan bantuan cacing) atau biasa digunakan sebagai cacing untuk mengolah limbah domestik (Huhta dan Haimi, 1988).

Sorghum merupakan tanaman yang dapat digunakan sebagai pangan, pakan dan bioenergi dan mempunyai kemampuan untuk beradaptasi dengan lingkungan (Suminar et al., 2017).

Mulsa digunakan untuk menutupi tanah dalam menciptakan iklim mikro yang baik di sekitar perakaran, mencegah tumbuhnya gulma, mengurangi pencucian unsur hara. Mulsa yang digunakan bisa berupa mulsa plastik atau jerami (Ardhona et al., 2013), sedangkan Abdullah (2009) menggunakan biomasa gulma Chromolaena odorata, baik secara tunggal atau dikombinasikan dengan feses ternak. Pemakaian mulsa dalam penelitian ini untuk mendapatkan kelembaban tanah yang sesuai bagi pertumbuhan cacing di dalam media dan menahan panas dari udara di lingkungan rumah kaca.

Tujuan penelitian ini adalah untuk mengevaluasi pemberian cacing $E$. foetida dan berbagai macam mulsa terhadap pertumbuhan dan kualitas tanaman S. bicolor.

\section{MATERI DAN METODA}

Penelitian dilakukan di rumah kaca Laboratorium Agrostologi, Departemen Ilmu Nutrisi dan Teknologi Pakan, Fakultas Peternakan, IPB, pada tahun 2017. Tanah yang digunakan adalah tanah latosol Dramaga (pH: 4,9, $\mathrm{Al}_{\mathrm{dd}}$ : 1,03 cmol.kg-1, KTK : 14,68 cmol. $\left.\mathrm{kg}^{-1}, \mathrm{~KB}: 26 \%\right)$. Rancangan penelitian ini adalah rancangan acak lengkap, pola faktorial $2 \times 3$. Faktor pertama adalah pemberian cacing $E$. foetida yaitu tanpa cacing (Co) dan diberi cacing 60 ekor pot $^{-1}$ (C60). Sedangkan faktor kedua adalah pemberian mulsa, yaitu tanpa mulsa (Mo), mulsa organik (M1), dan mulsa anorganik (M2). Mulsa organik yang digunakan adalah rumput Brachiaria humidicola kering dengan ketebalan pemberian mulsa $\pm 1 \mathrm{~cm}$, sedangkan mulsa anorganik adalah mulsa plastik. Mulsa plastik diberikan setelah benih tumbuh, dalam setiap pot ditumbuhkan 2 tanaman. Semua perlakuan dilakukan ulangan sebanyak tiga kali. Analisa data menggunakan program SPSS versi 22, uji lanjut untuk hasil sidik ragam yang nyata menggunakan uji Duncan.

Tanah dikeringkan dan diayak menggunakan ayakan dengan diameter lubang $0,5 \mathrm{~cm}$. Tanah $5 \mathrm{~kg}$ BKU dimasukkan ke dalam pot dan ditambahkan kapur $15 \mathrm{~g} \mathrm{pot}^{-1}$ dinkubasikan selama seminggu sebelum tanam. Cacing dewasa berumur 2 bulan (ukuran $\pm 5 \mathrm{~cm} \mathrm{ekor}^{-1}$, berat $\pm 0,35 \mathrm{~g} \mathrm{ekor}^{-1}$ ) dimasukkan sebanyak 60 ekor pot ${ }^{-1}$ ke dalam media tanam bersamaan dengan penanaman benih tanaman. Perlakuan yang diberi cacing, pakan cacing berupa feses sapi diberikan sebanyak 90 g pot $^{-1}$ setiap lima hari sekali. Feses diberikan pula pada media tanpa cacing (Co) dalam jumlah yang sama. Media disiram setiap hari menggunakan aquadest. Tanaman dipanen pada 60 HST

\section{HASIL DAN PEMBAHASAN}

\section{Tinggi Tanaman dan Jumlah Daun}

Tinggi tanaman dan jumlah daun selama pertumbuhan tanaman disajikan pada Gambar 1. Pada awal penanaman hingga 40 HST tidak terlalu terlihat antara pelakuan, tetapi pada saat panen pemberian cacing dengan mulsa organik menunjukkan pertumbuhan yang paling tinggi. Pada saat awal unsur hara hasil perombakan bahan organik belum cukup untuk memberikan perbedaan terhadap masing-masing perlakuan. Sifat dari vermicompost adalah bersifat melepaskan hara perlahan-lahan (slow release) (Chaoi et al., 2003)

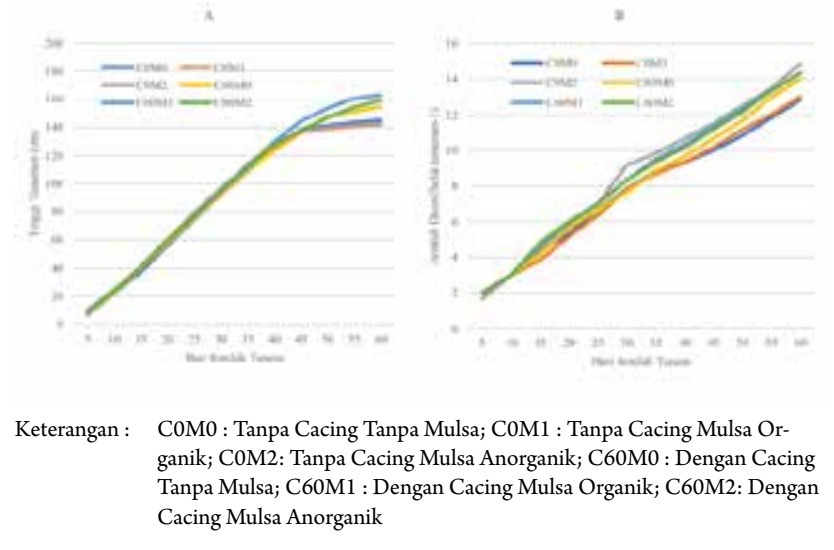

Gambar 1. Tinggi tanaman (A) dan jumlah daun (B) tanaman selama pertumbuhan 
Tabel 1. Berat Kering Batang Sorghum bicolor 6o HST

\begin{tabular}{|c|c|c|c|c|}
\hline \multirow[b]{2}{*}{ Faktor } & \multicolumn{3}{|c|}{ Mulsa } & \multirow[b]{2}{*}{ Rataan } \\
\hline & Tanpa Mulsa & $\begin{array}{c}\text { Mulsa } \\
\text { Organik }\end{array}$ & $\begin{array}{c}\text { Mulsa } \\
\text { Anorganik }\end{array}$ & \\
\hline Cacing & \multicolumn{4}{|c|}{ 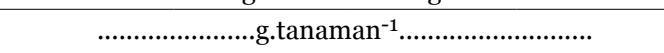 } \\
\hline Cacing o & $5,02 \pm 2,00$ & $5,39 \pm 0,40$ & $4,77 \pm 0,74$ & $5,12 \pm 1,04$ \\
\hline Cacing 60 & $5,24 \pm 1,52$ & $7,57 \pm 2,08$ & $6,14 \pm 0,90$ & $6,31 \pm 1,50$ \\
\hline Rataan & $5.22 \pm 1,76$ & $6,48 \pm 1,24$ & $5,50 \pm 0,82$ & \\
\hline
\end{tabular}

Tabel 2. Berat Kering Daun Sorghum bicolor 6o HST

\begin{tabular}{|c|c|c|c|c|}
\hline \multirow[b]{2}{*}{ Faktor } & \multicolumn{3}{|c|}{ Mulsa } & \multirow[b]{2}{*}{ Rataan } \\
\hline & Tanpa Mulsa & $\begin{array}{c}\text { Mulsa } \\
\text { Organik }\end{array}$ & $\begin{array}{c}\text { Mulsa } \\
\text { Anorganik }\end{array}$ & \\
\hline Cacing & \multicolumn{4}{|c|}{ 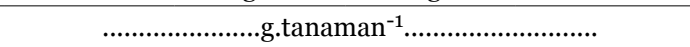 } \\
\hline Cacing o & $6,00 \pm 1,61$ & $6,57 \pm 0.38$ & $6,80 \pm 0,46$ & $6.46 \pm 0,82 B^{*}$ \\
\hline Cacing 6o & $7,74 \pm 2,29$ & $9,94 \pm 0,98$ & $9,27 \pm 0,32$ & $8,98 \pm 1,20 \mathrm{~A}$ \\
\hline Rataan & $6,87 \pm 1,95$ & $8,25 \pm 0,68$ & $8.04 \pm 0,39$ & \\
\hline
\end{tabular}

Tabel 3. Berat Kering Tajuk Sorghum bicolor 6o HST

\begin{tabular}{|c|c|c|c|c|}
\hline \multirow[b]{2}{*}{ Faktor } & \multicolumn{3}{|c|}{ Mulsa } & \multirow[b]{2}{*}{ Rataan } \\
\hline & $\begin{array}{l}\text { Tanpa } \\
\text { Mulsa }\end{array}$ & $\begin{array}{c}\text { Mulsa } \\
\text { Organik }\end{array}$ & $\begin{array}{c}\text { Mulsa } \\
\text { Anorganik }\end{array}$ & \\
\hline Cacing & \multicolumn{4}{|c|}{ 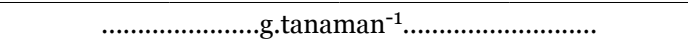 } \\
\hline Cacing o & $11,20 \pm 3,56$ & $11,95 \pm 0,75$ & $11,57 \pm 1,16$ & $11,57 \pm 0,82 B^{*}$ \\
\hline Cacing 60 & $12,97 \pm 3,76$ & $17,50 \pm 2,43$ & $15,40 \pm 0,82$ & $15,29 \pm 2,34 \mathrm{~A}$ \\
\hline Rataan & $12,09 \pm 3,66$ & $14,73 \pm 1,59$ & $13,49 \pm 0,99$ & \\
\hline
\end{tabular}

Tabel 4. Berat Kering Akar Sorghum bicolor 6o HST

\begin{tabular}{|c|c|c|c|c|}
\hline \multirow[b]{2}{*}{ Faktor } & \multicolumn{3}{|c|}{ Mulsa } & \multirow[b]{2}{*}{ Rataan } \\
\hline & $\begin{array}{l}\text { Tanpa } \\
\text { Mulsa }\end{array}$ & $\begin{array}{c}\text { Mulsa } \\
\text { Organik }\end{array}$ & $\begin{array}{c}\text { Mulsa } \\
\text { Anorganik }\end{array}$ & \\
\hline Cacing & \multicolumn{4}{|c|}{ 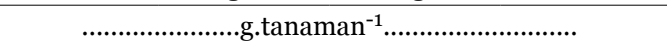 } \\
\hline Cacing o & $1,47 \pm 0,51$ & $1,57 \pm 0,25$ & $1,50 \pm 0,27$ & $1,51 \pm 0,34 \mathrm{~B}^{*}$ \\
\hline Cacing 60 & $1,64 \pm 0,70$ & $2,57 \pm 0,23$ & $2,17 \pm 0,16$ & $2,12 \pm 0,36 \mathrm{~A}$ \\
\hline Rataan & $1,55 \pm 0,61$ & $2,07 \pm 0,24$ & $1,84 \pm 0,21$ & \\
\hline
\end{tabular}

\section{Berat Kering Batang, Daun, Tajuk, dan Akar}

Berat kering batang, daun, tajuk dan akar disajikan pada Tabel 1 sampai dengan Tabel 4. Dari tabel tersebut terlihat bahwa pengaruh penambahan cacing sangat nyata meningkatkan berat kering daun, tajuk, dan akar. Aktivitas cacing di dalam media telah merombak bahan organik yang diberikan dalam bentuk feses sapi sebagai pakannya menjadi kotoran cacing yang kaya akan unsur hara. Unsur hara hasil dari proses kotoran cacing ini dimanfaatkan oleh tanaman untuk tumbuh dan menghasilkan biomasa tanaman. Sistem perakaran tanaman sorgum juga dapat berkembang dengan baik dengan penambahan cacing, hal ini ditunjukkan dengan biomasa akar yang berbeda sangat nyata $(\mathrm{P}<\mathrm{O}, 01)$ dibandingkan dengan biomasa akar pada media tanpa pemberian cacing (Tabel 4). Blouin et al. (2019) melalui studi metaanalisisnya 65\% dari literatur menyatakan biomasa akar meningkat dengan pemberian vermicompost.

\section{Akumulasi N, P, K Tajuk Tanaman}

Akumulasi nutrien merupakan hasil perkalian antara kandungan nutrien dengan berat keringnya. Dalam penelitian ini tajuk tanaman adalah gabungan antara batang dan daun. Akumulasi nutrien disajikan pada Tabel 5 sampai dengan dengan Tabel 6 . Umumnya pemberian cacing meningkatkan akumulasi nutrien. Terdapat interaksi antara cacing dengan mulsa terhadap akumulasi $\mathrm{N}$ tajuk. Akumulasi $\mathrm{N}$ tertinggi terdapat pada pemberian cacing dengan mulsa organik. Pemberian mulsa organik membuat kondisi media sesuai bagi perkembangan dan aktivitas cacing dalam melakukan perombakan bahan organik yang diberikan. Peningkatan akumulasi nutrien pada pemberian cacing ini disebabkan oleh peningkatan ketersediaan unsur hara di dalam tanah dengan adanya pemberian cacing pada media tanam. Pemberian cacing telah meningkatkan N, P, K tanah (Chaoi et al., 2003)

Tabel 5. Akumulasi N Tajuk Sorghum bicolor 6o HST

\begin{tabular}{|c|c|c|c|}
\hline \multirow[b]{2}{*}{ Faktor } & \multicolumn{3}{|c|}{ Mulsa } \\
\hline & $\begin{array}{l}\text { Tanpa } \\
\text { Mulsa }\end{array}$ & $\begin{array}{c}\text { Mulsa } \\
\text { Organik }\end{array}$ & $\begin{array}{c}\text { Mulsa } \\
\text { Anorganik }\end{array}$ \\
\hline Cacing & \multicolumn{3}{|c|}{ 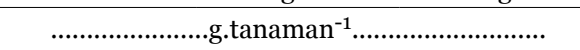 } \\
\hline Cacing o & $0,18 \pm 0.05 \mathrm{ab}$ & $0,18 \pm 0.02 a . . b$ & $0,17 \pm 0.05 b^{*}$ \\
\hline Cacing 60 & $0,10 \pm 0,01 b$ & $0,27 \pm 0,08 a$ & $0,16 \pm 0,06 b$ \\
\hline
\end{tabular}

*huruf yang berbeda pada menunjukkan perbedaan yang nyata $(P<0,05)$

Tabel 6. Akumulasi P Tajuk Sorghum bicolor 6o HST

\begin{tabular}{|c|c|c|c|c|}
\hline \multirow[b]{2}{*}{ Faktor } & \multicolumn{3}{|c|}{ Mulsa } & \multirow[b]{2}{*}{ Rataan } \\
\hline & Tanpa Mulsa & $\begin{array}{c}\text { Mulsa } \\
\text { Organik }\end{array}$ & $\begin{array}{c}\text { Mulsa } \\
\text { Anorganik }\end{array}$ & \\
\hline Cacing & \multicolumn{4}{|c|}{ 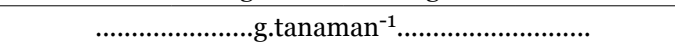 } \\
\hline Cacing o & $39,3 \pm 15,0$ & $37,1 \pm 4,3$ & $39,5 \pm 6,2$ & $38,6 \pm 8,5 b^{*}$ \\
\hline Cacing 60 & $48,2 \pm 14,3$ & $53,9 \pm 10,7$ & $49,7 \pm 6,3$ & $50,6 \pm 10,5 a$ \\
\hline Rataan & $43,7 \pm 14,7$ & $45,5 \pm 7,5$ & $44,6 \pm 6,3$ & \\
\hline
\end{tabular}

*huruf yang berbeda pada kolom yang sama menunjukkan perbedaan yang nyata $(P<0,05)$

Tabel 7. Akumulasi K Tajuk Sorghum bicolor 6o HST

\begin{tabular}{|c|c|c|c|c|}
\hline \multirow[b]{2}{*}{ Faktor } & \multicolumn{3}{|c|}{ Mulsa } & \multirow[b]{2}{*}{ Rataan } \\
\hline & $\begin{array}{l}\text { Tanpa } \\
\text { Mulsa }\end{array}$ & $\begin{array}{c}\text { Mulsa } \\
\text { Organik }\end{array}$ & $\begin{array}{c}\text { Mulsa } \\
\text { Anorganik }\end{array}$ & \\
\hline Cacing & \multicolumn{4}{|c|}{ 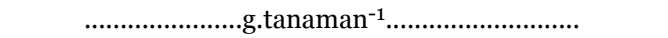 } \\
\hline Cacing o & $0,22 \pm 0,07$ & $0,28 \pm 0,03$ & $0,31 \pm 0,08$ & $0,27 \pm 0,06 b^{*}$ \\
\hline Cacing 60 & $0,35 \pm 0,11$ & $0,41 \pm 0,12$ & $0,38 \pm 0,01$ & $0,38 \pm 0,08 a$ \\
\hline Rataan & $0,29 \pm 0,09$ & $0,35 \pm 0,08$ & $0,34 \pm 0,05$ & \\
\hline
\end{tabular}

*huruf yang berbeda pada kolom yang sama menunjukkan perbedaan yang nyata $(P<0,05)$

\section{Populasi, Berat dan Kokon Cacing}

Hasil penghitungan populasi dan jumlah kokon serta berat cacing yang dihasilkan disajikan pada 
Gambar 2. Kokon merupakan kapsul pembungkus telur cacing, satu kokon terdiri dari beberapa telur. Setiap jenis cacing mempunyai bentuk dan ukuran kokon yang berbeda (Bhattacharjee dan Chaudhuri, 2002).
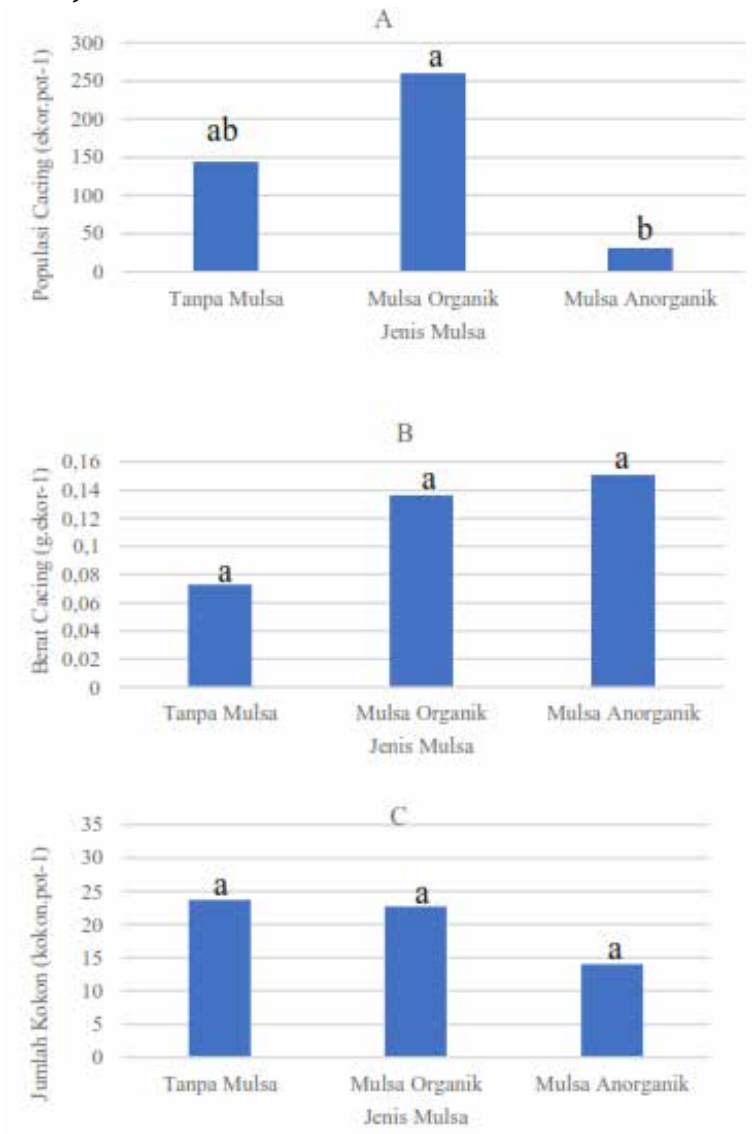

Keterangan : huruf yang berbeda di atas diagram batang pada masing-masing gambar menunjukkan perbedaan nyata $(\mathrm{P}<0,05)$

Gambar 2. Populasi cacing (A), berat cacing (B), dan jumlah kokon (C) pada saat panen

Populasi cacing yang diberikan mulsa organik menunjukkan perbedaan nyata $(\mathrm{P}<0,05)$ dengan populasi cacing pada media anorganik. Mulsa organik masih mengandung pori-pori sehingga cacing dapat berrespirasi dengan baik karena oksigen dapat masuk ke dalam tanah melalui pori-pori mulsa organik. Sedangkan pada mulsa anorganik terdapat hambatan dalam masuknya udara ke dalam tanah. Berat setiap cacing berkurang dibandingkan pada saat mulai dimasukkan ke dalam media pada awal pertanaman. Hal ini disebabkan karena persaingan jumlah makanan karena perhitungan jumlah pakan yang diberikan menggunakan perhitungan populasi awal.

\section{SIMPULAN DAN SARAN}

Simpulan dari penelitian ini adalah pemberian cacing mempunyai pengaruh positif dalam peningkatan produksi tanaman sorghum, sedangkan pengaruh mulsa tidak terlihat pada parameter tanaman, hanya terlihat pada pertumbuhan cacing. Pemberian mulsa organik sangat menunjang pertumbuhan cacing yang baik yang dicirikan dengan populasi cacing yang sangat tinggi.

Untuk melihat dinamika perubahan sifat fisik maupun kimia yang terjadi di dalam tanah akibat pemberian cacing diperlukan penelitian inkubasi menggunakan cacing bersamaan dengan penelitian pertumbuhan tanaman.

\section{DAFTAR PUSTAKA}

Abdullah L. 2009. Pola pertumbuhan rumput signal (Brachiaria humidicola (Rendle) Schwick) pada padang penggembalaan dengan aplikasi sumber nutrien berbeda. Media Peternakan 32(1): 71-80

Ardhona, S, K. Hendarto, A. Karyanto, dan Y.C. Ginting. 2013. Pengaruh pemberian dua jenis mulsa dan tanpa mulsa terhadap karakteristik pertumbuhan dan produksi tanaman cabai merah (Capsicum annum L) pada dataran rendah. J. Agrotek Tropika. 1(2): $153-158$

Bhattacharjee, G, dan P.S. Chaudhuri. 2002. Cocoon production, morphology, hatching pattern and fecundity in seven tropical earthworm species a laboratory-based investigation. J. Biosci. 27(3) 283-294

Chaoi, H. I., L.M. Zibilske, and T. Ohno. 2003. Effect of earthworm casts and compost on soil microbial activity and plant nutrient availability. Soil Biologi \& Biochemistry 35: 295-302

Djaenudin D. 2008. Perkembangan penelitian sumber daya lahan dan kontribusinya untuk mengatasi kebutuhan lahan pertanian di Indonesia. Jurnal Litbang Pertanian, 27(4): 137-145

Huhta V, and J. Haimi. 1983. Reproduction and biomass of Eisenia foetida in domestik waste.p 65-69 In C.A. Edwards and E.F. Neuhauser (Ed.). Earthworms in waste and environmental management. SPB Academic Publishing, the Hague, the Netherlands

Subandi, dan A Wijanarko. 2013. Pengaruh teknik pemberian kapur terhadap pertumbuhan dan hasil kedelai pada lahan kering masam. Penelitian Pertanian Tanaman Pangan 32 ( 3): 171-178

Suminar R, Suwarto, dan H Purnamawati. 2017. Pertumbuhan sorgum di tanah latosol dengan aplikasi dosis pupuk nitrogen dan fosfor yang berbeda. J. Agron. Indonesia. 45(3) 271-277

Wijanarko A, dan A Taufiq. 2004. Pengelolaan kesuburan lahan kering masam untuk tanaman kedelai. Buletin Palawija No 7 \& 8 : 39-50 